\title{
Numerical and Experimental Analysis of Residual Stresses in Full-Penetration Laser Beam Welding of Ti6Al4V Alloy
}

\author{
Liu Chuan, Zhang Jianxun, Niu Jing
}

Xi'an Jiaotong University, Xi'an 710049, China

\begin{abstract}
A 3D thermal elastic-plastic finite element model to predict welding residual stresses induced by full-penetration laser welding of Ti6Al4V alloy was described in detail. The welding experiments and residual stresses measurements by through-thickness hole-drilling method were also performed to validate the simulated results. A uniform conical heat source model with parameters taken from the actual weld seam dimensions was developed to simulate the welding temperature fields with different welding heat inputs. The thermal elastic-plastic finite element simulation was employed to calculate the welding residual stresses. The boundary conditions and the size of finite element mesh were also discussed. The results show that the cross section profiles of the weld seam simulated with the conical heat source based on the configuration of weld seam agree well with the experimental results; the zone of residual stresses distribution in laser full-penetration welding of Ti6Al4V alloy is very narrow and the gradient of longitudinal residual stress is very steep; the residual stresses distribution on the surfaces are different from those in the interior of the welding seam; the measured residual stresses by through-thickness hole-drilling method are similar to the simulated ones in the interior of the welding seam.
\end{abstract}

Key words: laser full-penetration welding; finite element; residual stresses; titanium alloy

Owing to higher processing speed, greater penetration, lower distortion and satisfied part accuracy that results from the concentrated heat source of the laser beam operating at relatively high velocity, the use of high power lasers for deep penetration welding has exhibited tremendous growth over the last decade for improving efficiency and reducing costs in a broad range of industries, such as shipbuilding, automobile and aerospace industries.

With modern computing facilities, the finite element technique has become an effective method for prediction and assessment of welding residual stresses. However, the accurate prediction of residual stresses and distortions induced by laser beam welding is extremely difficult. This is because not only the complicated phenomena involved in laser welding such as materials melting and evaporation, keyhole and plasma forming, laser absorption and reflection in plasma, but also the narrow weld seam needs more refined meshes to catch the greater temperature gradient and stress gradient, which will be spent much time to compute. Nevertheless, despite these complications, the simulation of laser welding has received a lot of attention in recent years and a significant progress has been made in this field, such as the residual stresses prediction in thick plate laser welding ${ }^{[1]}$, welding deformation prediction of different welding parameters ${ }^{[2,3]}$, investigation of cracks during welding ${ }^{[4]}$, optimization of welding parameters ${ }^{[5]}$, distortion prediction for laser micro-joining ${ }^{[6]}$ and deformation prediction of an automotive gear-case assembly ${ }^{[7]}$. All these references mentioned above have proved that the simulated results can be reliable for practical welding procedure without considering the complicated phenomena inside the keyhole formed.

Different welding parameters result in different configuration of weld seam. In this paper, a three-dimensional finite element model is presented to simulate the temperature fields and residual stresses of full-penetration laser welding of Ti6A14V alloy with different welding heat inputs. A Gaussian

Received date: July 28, 2008; Revised manuscript received date: March 11, 2009

Foundation item: Supported by the National Natural Science Foundation of China (50875200)

Biography: Liu Chuan, Candidate for Ph. D., Materials Science and Engineering School, Xi'an Jiaotong University, Xi'an 710049, P. R. China, Tel: 0086-29-82663115, E-mail: chuanliu2003@126.com 
distribution of heat flux is considered using a moving heat source in a conical shape modeled with the dimensions of weld seam obtained by experiments. A nonlinear thermo-mechanical analysis is performed using temperaturedependent material properties to calculate the residual stresses. Full-penetration welding experiments were carried out to get the weld seam configurations and residual stresses were measured by through-thickness hole-drilling method to validate the simulation model.

\section{Experiment Procedures}

The full-penetration laser welding experiments of Ti6Al4V alloy were performed with a $\mathrm{CO}_{2}$ laser at a maximum power of $3 \mathrm{~kW}$. The welding plate size was $200 \mathrm{~mm} \times 100 \mathrm{~mm} \times 4$ $\mathrm{mm}$. During the laser welding, the back of the plate and the melting pool were shielded by inert gas.

The through-thickness hole-drilling method was used to measure the residual stresses ${ }^{[8]}$. The positions of strain gauges for the welding with heat input of $115.7 \mathrm{~J} / \mathrm{mm}$ were designed, shown in Fig.1.

\section{Finite Element Model}

The full-penetration laser welding was simulated as a two thermal and mechanic steps. Firstly the non-linear heat transfer that produces the dynamic temperature distribution through the weld seam and plate was calculated. In the second step, the results of thermal analysis were applied as thermal body load on the welding plate, and the mechanical analysis was performed to calculate the stresses.

\subsection{Heat source model}

A cone-shaped volumetric heat source with Gaussian distri buted thermal energy density ${ }^{[4,9]}$ was used here as shown in Fig.2. Because the geometry of the fusion zone can be easily measured by experiments, thedimensions of fusion zone profile are taken as the mathematic parameters of the heat source model.

The heat flux of a point inside the cone can be computed according to equation (1):

$$
\left\{\begin{array}{c}
Q(x, y, z)=\frac{2 \eta P_{\mathrm{e}}}{\pi r_{\mathrm{e}}{ }^{2} H} \exp \left(\frac{-r^{2}}{r_{0}{ }^{2}}\right) \\
r^{2}=x^{2}+y^{2} \\
r_{0}=r_{\mathrm{i}}+\frac{\left(r_{\mathrm{e}}-r_{\mathrm{i}}\right) z}{H}
\end{array}\right.
$$

Where, $\eta$ is thermal efficiency, $r_{\mathrm{e}}$ is the half width of welding line at the top surface, and $P_{\mathrm{e}}$ is the laser power. $r_{\mathrm{i}}$ is the half width of the welding line on the bottom surface. $H$ is the welding penetration, for full penetration laser welding, which can be considered as the thickness of the plate.

\subsection{Geometry and mesh}

Because the welded plates are symmetrical about the weld center-line, only half of the plate is modeled. The dimensions

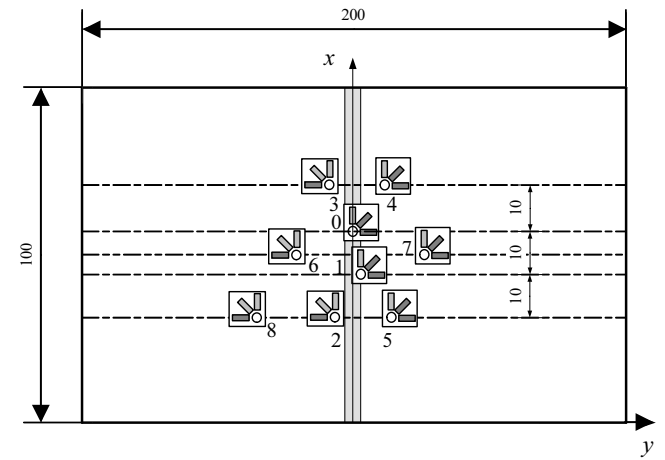

Fig.1 Schematic representation of strain gauge positions

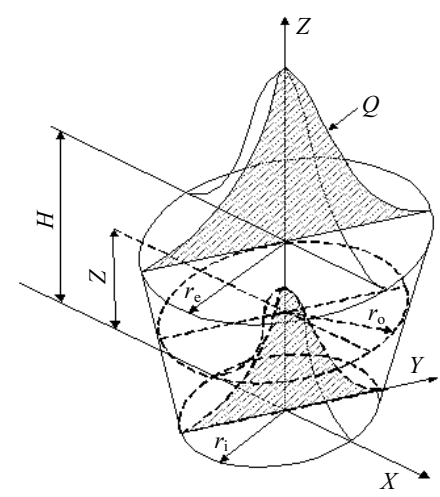

Fig.2 Power density distribution of the conical heat source

of the model were $100 \mathrm{~mm} \times 100 \mathrm{~mm} \times 4 \mathrm{~mm}$, and the model was meshed with eight-node brick elements for both thermal and mechanical analysis.

The welding line of laser welding is so narrow that sufficiently fine mesh is required in the weld line to capture the steep mechanical and thermal gradients. This often leads to an excessive discretization and consequently a huge computation time. Researchers had carefully investigated the mesh sensitivity to the simulated results. Tsirkas et al ${ }^{[2]}$ used four elements along the thickness for $4 \mathrm{~mm}$ thick plate laser welding; the edge of the smallest element was $0.3125 \mathrm{~mm}$ for $50 \mathrm{~mm} \times 30$ $\mathrm{mm} \times 5 \mathrm{~mm}$ model in reference [4]; the dimensions of the smallest element were $0.33 \mathrm{~mm} \times 0.5 \mathrm{~mm} \times 1 \mathrm{~mm}$ for $100 \mathrm{~mm}$ $\times 40 \mathrm{~mm} \times 7 \mathrm{~mm}$ model in reference [10]; the element dimensions of $0.1 \mathrm{~mm} \times 0.1 \mathrm{~mm} \times 0.1 \mathrm{~mm}$ for $11 \mathrm{~mm} \times 0.9 \mathrm{~mm} \times 5$ $\mathrm{mm}$ model was taken by Frewin and $\mathrm{Scott}^{[11]}$. In terms of accuracy and computing time, the smallest element with size of $0.2 \mathrm{~mm} \times 0.5 \mathrm{~mm} \times 1 \mathrm{~mm}$ was selected in our investigation. Fine meshes were generated in the critical fusion region near the weld area; the meshes were rather coarse in the regions remote from the joint. The final symmetrical plate model had total 24000 elements and 31155 nodes.

\subsection{Boundary conditions and material properties}

During the thermal analysis, boundary conditions including both convection and radiation were applied to all free surfaces of the model except for the symmetrical plane. Two kinds of convective heat transfer coefficients were presented in laser 
welding. The first one was the convection due to airflow and the second one was the convection due to the shielding inert gas. Combined boundary conditions were used here for heating and cooling stages, which accounted for the convection due to inert gas and radiation during heating stage and the convection due to airflow and radiation during cooling stage. Adiabatic boundary condition was imposed on the symmetrical plane.

During mechanical analysis, symmetrical boundary conditions were employed on the symmetrical plane. To prevent rigid body motion of the plate, the displacements of some nodes were constrained.

Temperature-dependent materials properties were assumed to be the same for both parent and fusion zone materials. The material was assumed to be thermo-elastic-plastic with rate independent plasticity. The von Mises yield criterion and the associated flow rule were used. Isotropic hardening was assumed. The material properties required for the present simulation were taken from references [12] and reference [13].

\section{Results and Discussions}

\subsection{Results of thermal simulations}

The full-penetration fusion zone profiles in the transverse direction obtained from experiments and the $1600{ }^{\circ} \mathrm{C}$ isothermal contour from the simulations for different welding heat inputs are shown in Fig.3.

As seen from Fig.3, different fused zone profiles were got with different welding heat inputs. The "nail" shape of the fusion zone was obtained with welding heat input of 115.7 $\mathrm{J} / \mathrm{mm}$, and "cup" shape with heat input of $162.0 \mathrm{~J} / \mathrm{mm}$. Fig.3 also shows that the computed fusion shapes agree fairly well with the experiments in the transverse direction with different welding heat inputs.

\subsection{Results of residual stresses simulations}

The residual stresses from measurements and simulation in the middle cross-section of the plates with welding heat inputs

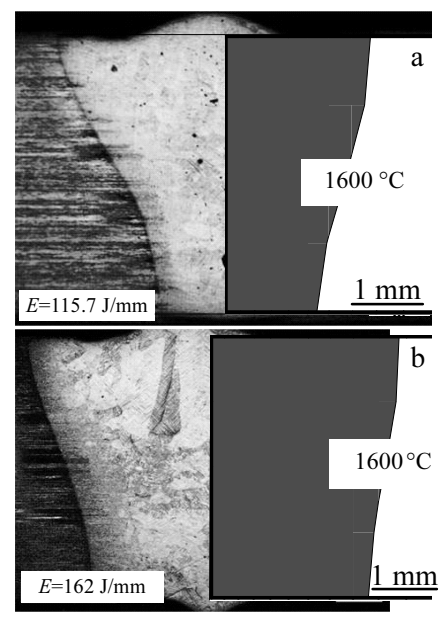

Fig.3 Comparison of fused zones between experiments and simulations: (a) heat input of $115.7 \mathrm{~J} / \mathrm{mm}$ and (b) heat input of $162 \mathrm{~J} / \mathrm{mm}$ of $115.7 \mathrm{~J} / \mathrm{mm}$ and $162 \mathrm{~J} / \mathrm{mm}$ are presented in Fig.4. The residual stresses of finite element simulation are presented at df ferent depths through the thickness.

From Fig.4, the longitudinal stress is tensile stress and is very large in the fusion zone with the small transverse residual stress in the same area; the longitudinal stress decreases rapidly with increasing of distance from the weld centerline, passing through zero at a small distance from the weld centerline and leading to balancing compressive stress of approximately 100-200 MPa in the far field. The width of the tensile longitudinal residual stress zone within the half plate is $5 \mathrm{~mm}$ with the heat input of $115.7 \mathrm{~J} / \mathrm{mm}$, and $8 \mathrm{~mm}$ with the heat input of $162.0 \mathrm{~J} / \mathrm{mm}$, respectively, which means that the stress gradient within

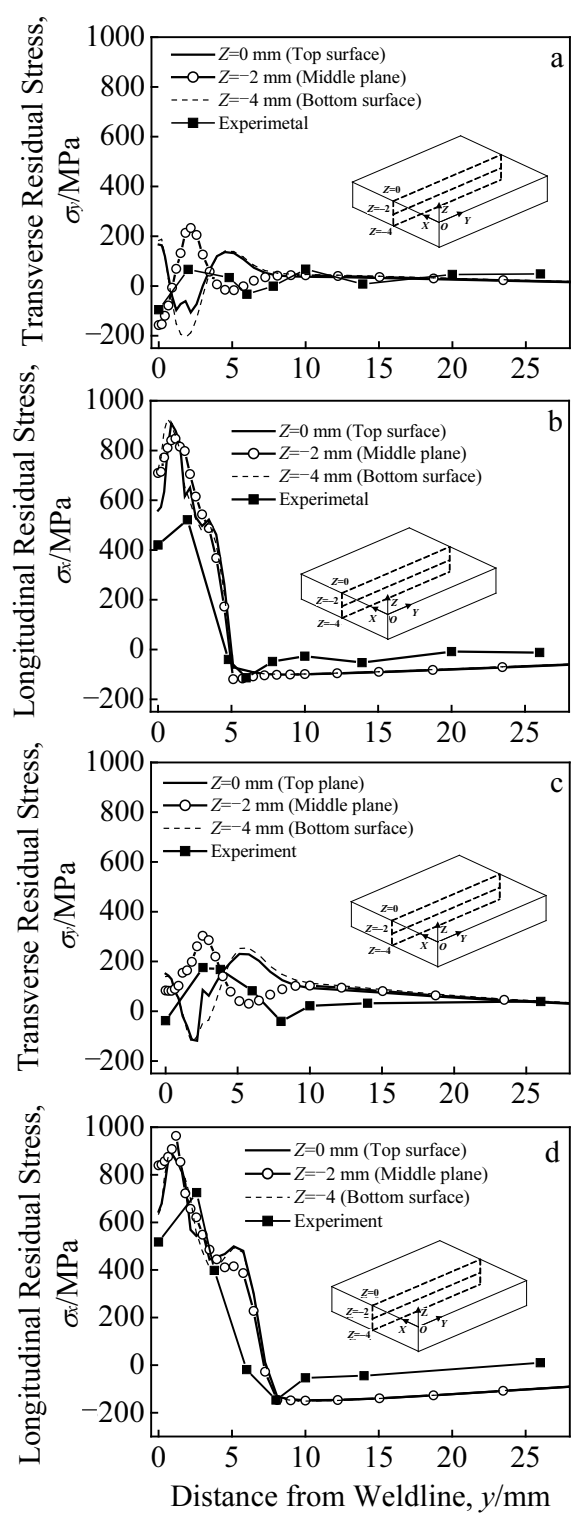

Fig.4 Comparison of simulation and experimental residual stresses: (a) transverse residual stress with heat input of $115.7 \mathrm{~J} / \mathrm{mm}$, (b) longitudinal residual stress with heat input of 115.7 $\mathrm{J} / \mathrm{mm}$, (c) transverse residual stress with heat input of 162.0 $\mathrm{J} / \mathrm{mm}$, and (d) longitudinal residual stress with heat input of $162.0 \mathrm{~J} / \mathrm{mm}$ 
the fusion zone of laser full penetration welding is very steep.

It can be seen from Fig.4 that the measured residual stresses are smaller than simulated ones around the weld zone, while close to each other far from the weld zone. The reason of the discrepancy between the measured and simulated stresses around the weld zone would be the discrepancy of material properties between the weld seam and the base metal. The materials properties of the weld seam have been changed with the large heating and cooling rates during laser welding.

Fig.4 also shows that the simulated distributions of transverse and longitudinal stresses on the top and bottom surfaces are similar, but different from those on the plane at the depth of $2 \mathrm{~mm}$. This discrepancy of the transverse residual stresses between locations near weld surfaces and at the center of the weld were also reported by Cho et $\mathrm{al}^{[14]}$ in laser welding $3.2 \mathrm{~mm}$ thick Ti6Al4V plate.

By carefully comparing the measured results with simulated ones in Fig.4, it can be concluded that the distributions of measured residual stresses are similar to the stresses on the plane at the depth of $2 \mathrm{~mm}$ except that the peak values of the simulated residual stresses are larger than those of measured residual stresses. The reason of the similar distributions between measured and simulated stresses at depth of $2 \mathrm{~mm}$ lies in the fact that the residual stresses measured by throughthickness hole-drilling method are the mean values of stresses through the thickness at the measuring position.

\section{Conclusions}

1) The uniform conical heat source accounting for the configuration of the fusion zone can be used to simulate the temperature field for full-penetration laser welding with df ferent heat inputs. The simulated cross section profiles agree well with the experimental ones.

2) The longitudinal residual stress gradient is very steep for laser full-penetration welding. The peak value of the longitudinal residual stress is very large with a small peak value of the transverse residual stress correspondingly.
3) The residual stresses distribution on top surface are similar to those on bottom surface, while different from those in the interior of the welding seam. The residual stresses measured by through-thickness hole-drilling method are similar to those in the interior welding seam in which the measured residual stresses by through-thickness hole-drilling method are the mean values of stresses in the measuring position through thickness.

\section{References}

1 Carmignani C, Mares R, Toselli G. Computer Methods in Applied Mechanics and Engineering[J], 1999, 179(12): 197

2 Tsirkas S A, Papanikos P, Kermanidis Th. Journal of Materials Processing Technology[J], 2003, 134(1): 59

3 Luo X, Shinozaki K, Kuroki H et al. Welding International[J], 2002, 16(5): 385

4 Ferro P, Bonollo F, Tiziani A. Science and Technology of Welding and Joining [J], 2005, 10(3): 299

5 Chang W S, Na S J. Journal of Materials Processing Technolo$g y[\mathrm{~J}], 2002,120(1-3): 208$

6 Tsirkas S A, Papanikos P, Pericleous K et al. Science and Technology of Welding and Joining [J], 2003, 8(2): 79

7 Zhang L J, Zhang J X, Kalaoui H et al. Journal of Materials Processing Technology[J], 2007, 190(1-3): 109

8 Zhang J X, Xue Y, Gong S L. Science and Technology of Welding and Joining [J], 2005, 10(6): 643

9 Darcout C, Roelandt J M, Rachik M et al. Journal de Physique IV [J], 2004, 120: 785

10 Lundbäck A, Runnemalm H. Science and Technology of Welding and Joining $[\mathrm{J}], 2005,10(6): 717$

11 Frewin M R, Scott D A. Welding Journal[J], 1999, 78(1): 15

12 Bonollo F, Tiziani A, Zambon A. Materials Science and Technology[J], 1993, 9(12): 1137

13 Li J, Guan Q, Shi Y W et al. Science and Technology of Welding and Joining[J], 2004, 9(5): 451

14 Cho J. R, Roberts S M, Reed R C. Proceedings of SPIE[J], 2003, 4831: 192

\title{
数值模拟和实验研究 Ti6Al4V 合金激光熔透焊接残余应力
}

\author{
刘川, 张建勋, 牛 靖 \\ (西安交通大学, 陕西 西安 710049)
}

摘 要: 采用热-弹塑性三维有限元法研究激光熔透焊接 Ti6Al4V 合金的残余应力, 并采用小孔法测量焊接残余应力以和计算结果进行 比较。有限元计算时, 建立了以焊缝形貌尺寸为参数的统一雉形热源模型来模拟不同热输入时的焊接温度场, 并讨论了边界条件和有限 元网格大小的确定。研究结果表明: 采用焊缝轮廓尺寸作为热源参数能准确模拟焊缝横截面轮廓; 钛合金激光熔透焊接的纵向残余应力 分布梯度陡; 在焊件表面和内部残余应力分布趋势不同，采用小孔法测量的残余应力分布和计算的焊接件内部残余应力分布相似。 关键词：激光熔透焊接；有限元；残余应力；钛合金

作者简介: 刘 川, 男, 1977 年生, 博士生, 西安交通大学材料科学与工程学院, 陕西 西安 710049, 电话: 029-82663115, E-mail: chuanliu2003@126.com 